\title{
Microanalysis of Antigorite in Brake Pads
}

I Martínez-Pérez ${ }^{1}$, EE Vera-Cárdenas ${ }^{2 *}$, G Luis-Raya $^{1}$, G Villagomez-García $^{1}$, M Villanueva-Ibánez ${ }^{1}$ and FG Mejía-Hernández ${ }^{3}$

1. Universidad Politécnica de Pachuca, Carretera Pachuca-Ciudad Sahagún km 20, Ex-Hacienda de Santa Bárbara, Zempoala, Hgo., México.

2. Tecnológico Nacional de México/I. T. Pachuca, Carretera México-Pachuca Km. 87.5, Colonia Venta Prieta, Pachuca de Soto, Hgo., México.

3. Universidad Autónoma del Estado de Hidalgo, Carretera Pachuca-Tulancingo Km 4.5, Colonia Carboneras, Mineral de la Reforma, Hgo., México.

*Corresponding author: eevc2000@hotmail.com

It is essential that the braking systems of all the different types of vehicles have the right elements and quality, because it directly impacts the safety of the crew. In this case we focus on the brake pads, which can be found in the market with different characteristics with respect to its chemical composition that directly influences the performance characteristics[1,2]. For many years, brake pads have used different compositions, from asbestos to materials of natural origin [3]. Some of the most common compositions for their mechanical and thermal properties contained in brake pads are iron oxides, quartz, silica, zirconium silicate, graphite, metal oxides, mineral fillers, molybdenum disulphide, asbestos, calcium carbonate, fibers and zinc oxide [4].

The samples were taken from a commercial brake pads, which were cut with a size of 10x10 mm. Tribological displacement tests were carried out to determine its resistance to wear, the conditions in dry and at room temperature of the test were a load of $2.84 \mathrm{~N}$, frequency of $10 \mathrm{~Hz}, 18,000$ cycles and a sliding distance of $3 \mathrm{~mm}$, representing a distance traveled of $108000 \mathrm{~mm}$. The study carried out was based on SEM, EDS and XRD, these characterization techniques allowed us to determine the antigorite and the others compositions present in the brake pads.

In Figure 1 some regions with irregular and fibrous morphology were observed, corresponding to the presence of asbestos located inside the wear scars formed on the surface of the specimen by the displacement test. Figure 2 corresponds to the SEM map on the surface, showing the elements corresponding to the composition of the brake pad analyzed. In the XRD pattern shown in Figure 3, the presence of the phases of asbestos type antigorite $\left(\mathrm{Mg}_{3} \mathrm{Si}_{2} \mathrm{O}_{5}(\mathrm{OH})_{4}\right.$, PDF: 44-1447), rosenhahnite $\left(\mathrm{Ca}_{3} \mathrm{Si}_{3} \mathrm{O}_{8}(\mathrm{OH})_{2}\right.$, PDF: 29-0378) silicon $\left(\mathrm{SiO}_{2}\right.$, PDF: 74-0445) oxide, graphite (C, PDF: 74-2329) and calcite $\left(\mathrm{CaCO}_{3}, \mathrm{PDF}: 05-0586\right)$ is verified.

References:

[1] SN Nagesh et al., Procedia Mater Sci 5 (2014), p. 295. doi:10.1016/j.mspro.2014.07.270.

[2] M Zaki Bahrom et al., Int J Adv Sci Eng Inf Technol 6 (2016), p. 553. doi:10.18517/ijaseit.6.4.906.

[3] F Amato et al., Macla Rev La Soc Española Mineral 16 (2012), p. 154.

[4] MBY Ut-battelle, Compositions, Functions, and Testing of friction Brake materials (2001), p. 27. 


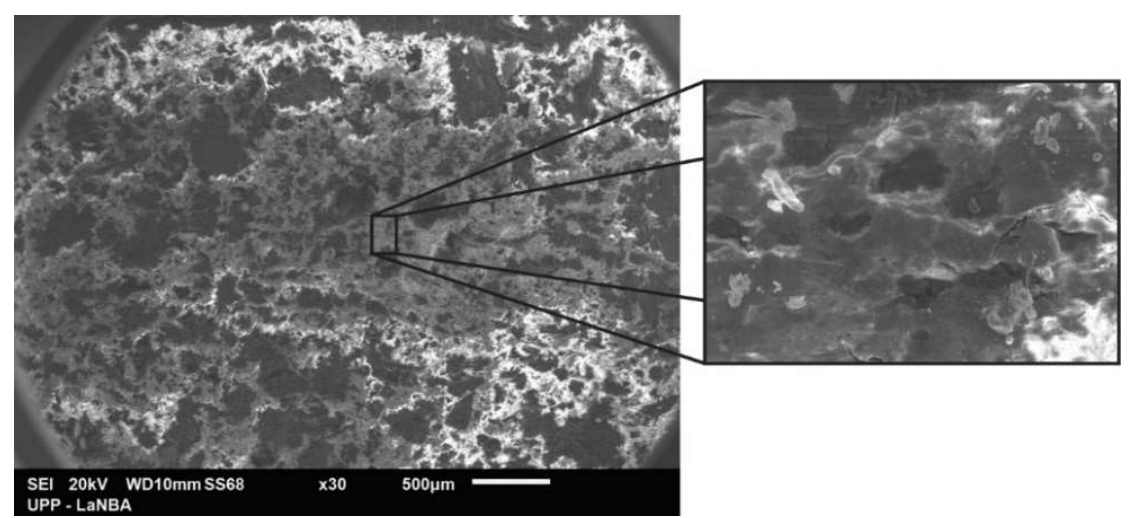

Figure 1. SEM micrograph inside the wear scars
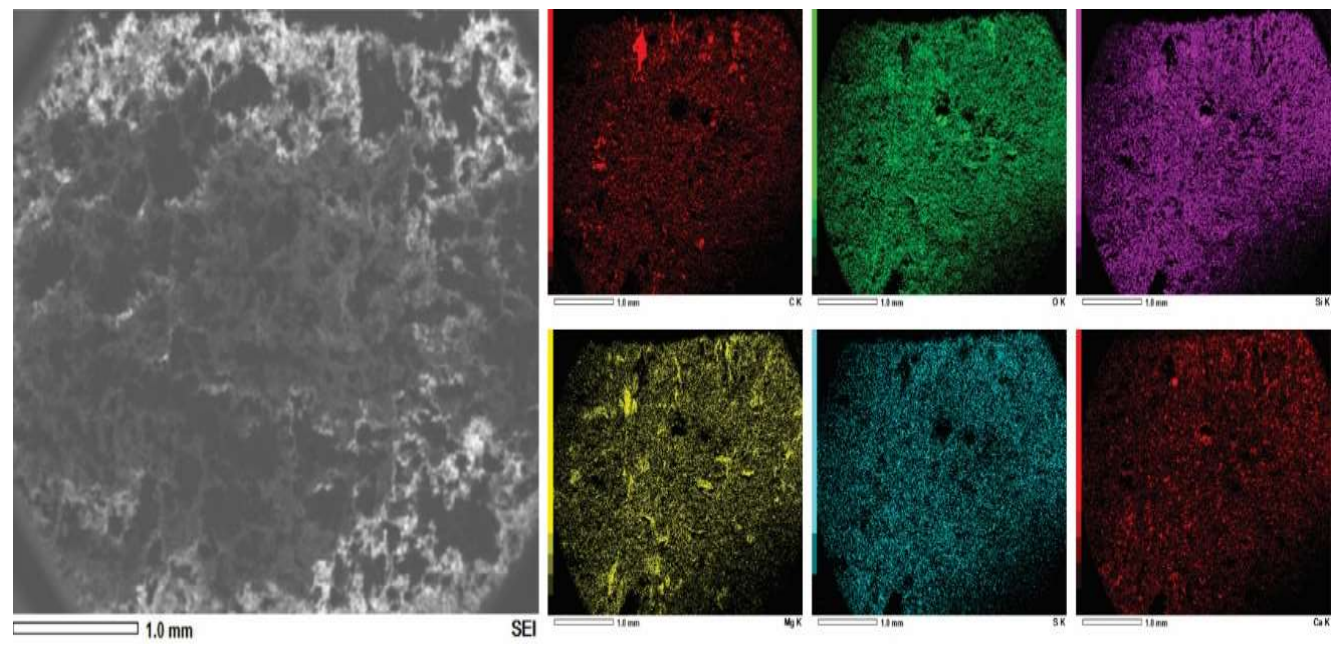

Figure 2. SEM micrograph maps

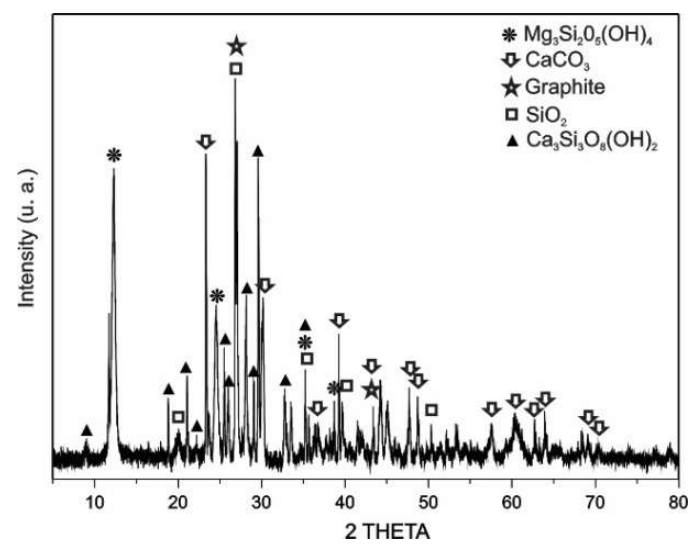

Figure 3. XRD diffraction pattern 